\title{
A LONGITUDINAL EVALUATION OF SENSITIVITY TRAINING WITHIN THE EDUCATIONAL MILIEU ${ }^{1)}$
}

\author{
Roger E. Kirk, J. David Johnson, and Rex R. Selters \\ Baylor University
}

\begin{abstract}
The student unrest that has disrupted college campuses across the country indicates a need for innovations in educational curricula and for improved communication among students, faculty, and administration. Efforts have been made to alter the image of the seemingly impervious and unresponsive academic structure whose programs are irrelevant to the social problems of today. One popular approach to the communication problem is sensitivity training based on the $\mathrm{T}$-group model developed by Kurt Lewin and his associates. Initial evaluations of sensitivity training based largely on anecdotal reports have been so favorable that the number of programs inaugurated each year has increased exponentially. However, psychologists accustomed to rigorously evaluating new ideas remain skeptical. Clearly some basic
\end{abstract} questions should be answered. Does training based on the $\mathrm{T}$-group model produce measurable changes in attitudes and/or behavior? If so, what types of changes occur and how persistent are they? How can such training be used to further the educational goals of colleges and universities?

Researchers realize that objective answers to such questions are difficult to obtain because of the methodological problems inherent in the assessment of behavioral change. Such research shares all the problems associated with research on psychotherapy in addition to some of its own, according to Miles (1960). Dunnette and Campbell (1968) indicate that two major methodological problems are employment of adequate controls and selection of sensitive measurement instruments. The former problem can be partially solved by using multiple control groups in a quasi-experimental design as described by Campbell and Stanley (1966). Selecting measuring instruments is more difficult because of the unstructured nature of training groups, their uniqueness, and the diversity of results claimed for them.

A number of experiments have been conducted to evaluate sensitivity training within the educational milieu. Culbert and Culbert (1968) found that sensitivity training on the UCLA cam. pus had minimized stereotypes which obstructed learning, had facilitated communication, and had helped students deal more effectively with authority figures. Geitgey (1966) compared the effects of sensitivity training and lecture-discussion on the subsequent performance of students in a nurses training program. She found that the sensitivity training group excelled both the lecturediscussion group and the control group on such criteria as patient and instructor evaluations and interpersonal relationships. Orsburn (1966) found sensitivity training to be more effective than lecture-discussion sessions in improving the class room behavior of 84 sophomore high school students. Lee(1967) reported that elementary school teachers who participated in a sensitivity training program showed a greater increase in favorable attitudes on the Minnesota Teacher Attitude Inventory than a comparable group of teachers who received conventional classroom instruction in human relations.

Longitudinal studies of the effects of sensitivity training are rare. Harrison (1966) conducted one such study designed to investigate the effects of sensitivity training on interpersonal awareness and found that the participants demonstrated more change three months after training than they had three weeks after training.

The research described in this paper was designed to evaluate the immediate and long-term effects of two sensitivity training laboratories conducted for Baylor Univertity students.

1) This research was supported by a grant from the Hogg Foundation for Mental Health. The suggestions and support of H. Paul Kelley and Joseph V. West are gratefully acknowledged. 
Kirk, R.E., et.al: A longitudinal evaluation of sensitivity training

\section{Method}

A pretest-posttest quasi-experimental design was used to assess attitudinal and personality changes attributable to participation in a sensitivity training laboratory. Two laboratories, Experiment $\mathrm{A}$ and Experiment $\mathrm{B}$, were conducted one year apart at an isolated retreat 240 miles southwest of Baylor's Waco campus. The laboratories were conducted by two experienced trainers from other universities.

The students who attended laboratories and the alternates who did not attend were selected by campus organizations. Each organization was asked to determine its own selection criteria and to apply the same criteria in choosing both participants and alternates. Students who attended the laboratories composed the experimental groups; students designated as alternates who did not attend the laboratories composed four of the control groups. The composition of the groups and the assessment instruments used to evaluate the effects of sensitivity training are discussed separately for Experiment $\mathrm{A}$ and Experiment $\mathrm{B}$.

Experiment $A$

A total of 165 students, 67 males and $98 \mathrm{fe}$ males, participated in the first experiment, which included two experimental groups and five control groups.

Subjects in experimental groups A-1 and A2 , described below, took the pretest and participated in the laboratory as a single group; they differed only in the interval between the laboratory and the posttest.

Experimental Group $A-1$. These students $(N=25)$ were a random sample of participants in the first laboratory. They took the pretest one week prior to the laboratory and the posttest approximately one week after the laboratory. The purpose of the group was to provide data for evaluating the immediate effects of the laboratory.

Experimental Group $A-2$. The remaining participants $(N=24)$ in the first laboratory took the pretest one week prior to the laboratory and the posttest approximately three months after the laboratory. The purpose of the group was to provide data for evaluating the persistence of effects of the laboratory.

The following two groups had the same pretest-posttest schedule as Experimental Group A-1 and served as its control groups.

Control Group $A-1$. 1. These students ( $N=$ 16) were selected by the campus organizations as being representative of participants in the laboratory.

Control Group A-1.2. These students ( $N=$ 24) were randomly selected from an advanced English literature class in order to provide data concering attitudinal and personality changes attributable to participation in a closely knit informally organized class.

The following three groups had the same pretest-posttest schedule as Experimental Group A-2 and served as its control groups.

Control Group $A-2.1$. These student ( $N=$ 16) were selected by the campus organizations as being representative of the participants in the laboratory.

Control Group A-2.2. These students ( $N=$ 21) were the remaining students in the advanced English literature class.

Control Group $A-2.3$. These students ( $N=$ 39) were enrolled in an introductory psychology course and provided data concerning changes attributable to contemporary events to which the student body at large was exposed during the interval between the pretest and posttest. Unlike Control Groups A-1.2 and A-2.2, these students rarely interacted with each other during class and gave no evidence of developing a class esprit de corps.

The test battery for Experiment A consisted of the following instruments:

1. The Developmental Status and Social Maturity scales from the Omnibus Personality Inventory (OPI).

2. Four scales known as the Social Welfare Human Relations Cluster (Affiliation, Conjunctivity, Nurturance, and Succourance) from the College Characteristic Index (CCI).

3. A nineteen-item sentence completion test constructed to measure attitudes toward specific campus issues at Baylor University.

\section{Experiment $B$}

One Hundred twenty-seven students, 63 males and 64 females, participated in the second experiment.

Subjects in experimental groups B-1 and B- 
2 took the pretest and participated in the laboratory as a single group; they differed only in the interval between the laboratory and the posttest.

Experimental Group B-1. These student ( $N$ $=28$ ) were a random sample of participants in the second laboratory. They took the pretest approximately one week prior to the laboratory and the posttest approximately one week after the laboratory. The purpose of the group was to provide data for evaluating the immediate effects of the laboratory.

Experimeutal Group $B-2$. The remaining participants $(N=25)$ in the second laboratory took the pretest one week prior to the laboratory and the posttest approximately ten weeks after the laboratory. The purpose of the group was to provide data for evaluating the persistence of effects of the laboratory.

The following group had the same pretestposttest schedule as Experimental Group B-1 and served as its control group.

Control Group $B-1$. 1. These student ( $N=$ 27) were a random sample of the alternates nominated by campus organizations who did not attend the second laboratory.

The following two groups had the same pretest-posttest schedule as Experimental Group B-2 and served as its control groups.

Control Group $B-2.1$. These students $(N=$ 22) were the remaining alternates to the second laboratory who did not attend.

Control Group B-2.2. These students ( $N=$ 25) were selected by campus organizations as being representative of participants in the laboratory. The purpose of the groud was to provide data concerning changes attributable to contemporary events to which the student body at large was exposed during the interval between the pretest and posttest.

The test battery for Experiment B consisted of the following instruments:

1. The Developmental Status scale from the Omnibus Personality Inventory (OPI).

2. The Ascendancy, Responsibility, Emotional Stability, and Sociability scales from the Gordon Personal Profile (GPP).

3. A twenty-item sentence completion test designed to measure interpersonal and intrapersonal relationships.
The sentence completion tests used in Experiments A and B were scored by three psychologists using a scoring by example procedure developed by Kirk (Chason, Kirk, and Wofford, 1957). Inter-rater reliability coefficients ranged from 81 to 93 .

\section{Results}

Data from the seven psychological scales in Experiment $\mathrm{A}$ and the six scales in Experiment $\mathrm{B}$ were analyzed using a completely randomized factorial analysis of covariance design (Kirk, 1968). The independent variables were sex and group; the concomitant variable was the subject's initial pretest score.

The psychological scales for which the group $F$ test statistics were significant, $p<.05$, are listed in Table 1. Comparisons between experimental and control posttest means were performed using Dunnett's test statistic (Dunnett, 1955). The posttest means were adjusted for the concomitant variable, pretest mean, prior to performing the comparisons. In this analysis of covariance design, differences between adjusted posttest means sig. nify a differential change from the pretest to the posttest for laboratory participants and nonparticipants. Table 1 presents the differences between adjusted and experimental and control group means.

The independent variable of sex was analyzed using the covariate adjustment described previously. Adjusted posttest means were higher for males than for females on the Developmental Status scale (OPI) but lower on the Affiliation scale (OPI), $F(1,150)=4.93, p<.05$, and $F(1$, $150)=4.80, p<.05$, respectively. On the sentence completion stems, "Actions by the Student Congress. .". and "The religious emphasis at Baylor...," the mean attitude of males was less favorable than that of females, indicating less change for males than for females. The $F$ test statistics for these two stems were, respectively, $F(1,150)=8.21$, $p<.01$, and $F(1,150)=4.24, p<.05$. The attitudes of males were more favorable than those of $\mathrm{fe}$ males on the sentence completion stem, "Laboratory facilities..., " $F(1,150)=4.24, p<.05$. In Experiment $B$, males received higher scores than females on the Emotional Stability scale (GPP), $F(1,116)$ $=4.62, p<.05$. The responses of males were more 
Kirk, R.E., et. al: A longitudinal evaluation of sensitivity training

Table 1

Comparisons Among Adjusted Means for Experimental and Control Groupsa)

Experiment A

\begin{tabular}{|c|c|c|c|c|c|c|c|}
\hline Scale & \multicolumn{2}{|c|}{ Group } & $\begin{array}{l}\text { Control } \\
\mathrm{A}-1.1\end{array}$ & $\begin{array}{l}\text { Control } \\
\mathrm{A}-1.2\end{array}$ & $\begin{array}{l}\text { Control } \\
\text { A-2.1 }\end{array}$ & $\begin{array}{l}\text { Control } \\
\text { A-2.2 }\end{array}$ & $\begin{array}{l}\text { Control } \\
\text { A-2.3 }\end{array}$ \\
\hline Developmental & Exp & A-1 & 2.12 & -.56 & & & \\
\hline Status (OPI) & Exp & A-2 & & & $9.54 * * *$ & 1.88 & $4.28 * * *$ \\
\hline Conjunctivity & Exp & $A-1$ & .73 & $1.04 *$ & & & \\
\hline$(\mathrm{CCI})$ & Exp & A-2 & & & $1.05^{*}$ & $1.91^{* * *}$ & .01 \\
\hline Sentence Completion & Exp & $A-1$ & $11.52^{* *}$ & $14.04 * *$ & & & \\
\hline Item $^{b)}$ & Exp & A-2 & & & $15.70^{* *}$ & $10.35 *$ & 6.94 \\
\hline Sentence Completion & Exp & A-1 & $19.23^{* *}$ & 18. $78^{* *}$ & & & \\
\hline Item () & $\operatorname{Exp}$ & A-2 & & & -4.04 & -4.64 & 5.56 \\
\hline
\end{tabular}

Experiment B

\begin{tabular}{|c|c|c|c|c|}
\hline Scale & Group & $\begin{array}{l}\text { Control } \\
\text { B-1.1 }\end{array}$ & $\begin{array}{l}\text { Control } \\
\text { B-2.1 }\end{array}$ & $\begin{array}{l}\text { Control } \\
\text { B-2.2 }\end{array}$ \\
\hline Developmental & Exp B-1 & 1.39 & & \\
\hline Status (OPI) & Exp B-2 & & 1.49 & $4.12^{* *}$ \\
\hline
\end{tabular}

a) Tabled values are differences between adjusted means ( $\bar{X}$ Exp. $-\bar{X}$ Cont. ).

b) "Actions by the Student Congress...".

c) "It is necessary to belong to an organization...".

$* p<.10, \quad * * p<.05, \quad * * * p<.01$.

positive than those of females on sentence completion items, "I.ooking ahead a few years, I...," $F(1,116)=4.58, p<.05$, and "Life in general...," $F(1,116)=4.92, p<.05$. All tests of sex by group interactions were insignificant.

\section{Discussion and Conclusions}

In order to minimize the confounding effects of extraneous variables that could jeopardize the internal validity of the experiment a quasi-experimental design with multiple control groups was used. Neither random assignment of subjects to the experimental and control groups nor precise matching of the groups was possible since campus organizations nominated the laboratory participants and alternates.

An examination of the data indicated that changes did occur in the students who attended the laboratory. The change of greatest interest was measured by the Developmental Status scale of the OPI. According to Heist and Williams (1957) students who obtain high scores on this scale tend to have attitudes similar to college seniors; low scores are associated with attitudes characteristic of younger students. Students who participated in the training laboratories obtained higher scores on the posttest Developmental Status scale than did their counterparts in the control groups. This suggests that the laboratories expedited the formation of attitudes which normally develop during college years. Thus these laboratories were instrumental in achieving some of the general objectives of the university. Comparable results were obtained by Spector (1958) in a study designed to measure changes in human relations attitudes attributable to sensitivity training.

Spector found that as a result of training, the students' attitudes became more like those of top field officers.

In both Experiment $\mathrm{A}$ and Experiment $\mathrm{B}$, higher scores were obtained by the participants on the Developmental Status scale when the posttests were administered approximately three months after the laboratories than when they were administered immediately afterwards. These findings, which are consistent with those of Harrison 
(1966), could be explained in terms of the time that is necessary for assimilation and integration of new attitude patterns. Students returned to the campus unsure of how their new ideas would be received in the college culture. It was hypothesized that 10 to 12 weeks of reality testing in the permissive environment of a college campus provided sufficient time either for assimilation of such changes in attitude or for development of a willingness to overtly express them.

The experimental groups of the first laboratory obtained higher scores on the posttest Conjunctivity scale than did the control groups. Anecdotal reports by both faculty and students indicate that these changes were accompanied by a number of important changes in the behavior of the students after they returned to the campus. One example will illustrate the nature of these changes. Prior to the laboratory, students sat together in the university cafeterias according to club affiliation; this in effect was an informal status system. Following the laboratory, students frequently sat with members of other clubs and nonclub members. This suggests that changes in the students' attitudes as measured by the Conjunctivity scale were accompanied by changes in established behavior patterns.

It was anticipated that students who attended the laboratory would increase in tolerance of others, acceptance of others, and capacity for mature criticism of institutionalized authority.

Data from the Developmental Status scale provide support for these hypotheses. Further support is provided by data from the Sentence Completion stem "Actions by the Student Congress..." on which laboratory participants expressed more positive attitudes than nonparticipants. It is of interest that males who attended the laboratory were uniformly less favorable than females on this stem and on the stem "The religious emphasis at Baylor...," but were more favorable on the stem "Laboratory facilities..."

The present experiments were designed to investigate the efficacy of sensitivity training in developing those attitudes and skills that further effective communication. It was concluded that sensitivity training within the educational milieu can lead to improve communication, an increase in maturity, and greater acceptance of others.

\section{REFERENCES}

Campbell, D. T., \& Stanley, J.C. 1966 Experimental and Quasi-Experimental Designs for Re-search. Chicago: Rand McNally,

Chason. L. R., Kirk, R. E. , \& Wofford, J. 1966 Student Officer Attitudes toward the Air Force, WADD Technical Report, AD 643686 ,

Culbert, S. A., \& Culbert, J. 1968 Sensitivity training within the educational framework: a means of mobilizing potential. J. Creat. Behav. 2, 14-30.

Dunnett, C. W. 1955 A multiple comparison procedure for comparing several treatments with a control. J. Amer. Stat. Associ. 50, 10961121.

Dunnette, M. D. , \& Campbell, J. P. 1968 Laboratory education: impact on people and organizations. Industrial Relat. 8, 1-27.

Geitgey, D. A. 1966 A study of some effects of sensitivity training on the performance of students in associate degree programs of nursing education. Unpublished doctoral dissertation, University of California at Los Angeles,

Harrison, R. 1966 Cognitive change and participation in a sensitivity-training laboratory. J. Counsel. Psychol., 30, 317-520.

Heist, P., \& Williams, P. 1957 Manual for the Omnibus Personality Inventory. University of California, Berkeley: Center for the Study of Higher Education,

Kirk, R. E. 1968 Experimental Design: Procedures for the Behavioral Sciences. Belmont, California: Brooks/Cole Publishing Co.

Lee, W.S. 1967 A study of the effectiveness of sensitivity training in inservice teacher-training program in human relations. Unpublisheddoctoral dissertation, University of California at Los Angeles,

Miles, M. B. 1960 Human relations training: process and outcomes. J. Counsel. Psychol., 7, 301-306.

Orsburn, J. D. 1966 Sensitivity training versus group lectures with high school problem students. Unpublished doctoral dissertation, Kent State University.

Spector, A. 1958 Changes in human relations attitude. J. Appl. Psychol., 42, 154-157. 
Kirk, R.E., et al: A longitudinal evaluation of sensitivity training

\title{
A LONGITUDINAL EVALUATION OF SENSITIVITY TRAINING WITHIN THE EDUCATIONAL MILIEU
}

\author{
ROGER E. KIRK, J. DAVID JOHNSON \\ AND REX. R. SELTERS \\ Baylor University
}

\begin{abstract}
The present research investigated the efficacy of sensitivity training in developing attitudes and skills which can further effective communication on the college campus. Two sensitivity training laboratories were conducted a year apart for Baylor University students. A pretestposttest quasi-experimental design was used in which the posttest was administered either immediately following or approximately three months after the laboratory. Changes attributable to the laboratories were measured by objective personality and attitude tests and sentence completion
\end{abstract}

tests.

It was concluded that sensitivity training was instrumental in producing attitudinal and personality changes in the participants. These changes appeared to be relatively enduring and in some cases were greater three months after the laboratory than immediately afterwards. Students who attended the laboratory returned to the campus with attitudes and personality responses that were similar to those of college seniors. The participants increased in their tolerance of others, acceptance of others, and capacity for mature criticism of institutionalized authority. 